\title{
SUNDMAN'S INEQUALITIES IN N-BODY PROBLEMS AND THEIR APPLICATIONS
}

\author{
ZHANG SHIQING
}

\begin{abstract}
In this paper, we study the necessary and sufficient conditions which make Sundman's inequalities become equalities and the relationships between the period and energy and angular momentum and the momentum of inertia for uniformly rotating planar circular solutions and the straight line solutions of $\mathrm{N}$-body problems with homogeneous potentials.
\end{abstract}

Mathematics subject classification (2000): 34C25, 34C15, 58F, 70F10. inertia.

Key words and phrases: N-body problems, period, energy, angular momentum, the momentum of

\section{REFERENCES}

[1] Abraham R. And Marsden J., Foundations of Mechanics, 2nd ed., Benjamin/Cummings, London, 1978.

[2] Arnold V., Kozlov V. And Neishtadt A., Dynamical Systems, III, Springer, Berlin, Russian ed. 1985, English ed. 1988.

[3] Meyer K. ANd Hall G., Introduction to Hamiltonian Systems and the N-body Problems, Springer, Berlin, 1992.

[4] Pollard, H., Mathematical Introduction to Celestial Mechanics, Prentice Hall, Englewood Cliffs, NJ., 1976.

[5] Siegle C. And Moser J., Lectures on Celestial Mechanics, Springer, Berlin, 1971.

[6] Sundman, K. F., Mémoire sur le problème des trois corps, Acta Math. 36 (1913), 105-179. 